\title{
On the Design of Remote Health Monitoring System
}

\author{
Mohanad Abdulhamid ${ }^{1}$ and Muchisu Albert ${ }^{2}$ \\ ${ }^{1}$ AL-Hikma University, Iraq,e-mail: moh1hamid@yahoo.com \\ ${ }^{2}$ University of Nairobi, Kenya, e-mail: researcher12018@yahoo.com
}

\begin{abstract}
With improvement in technology and miniaturization of sensors, there have been attempts to utilize the new technology in various areas to improve the quality of human life. One main area of research that has seen adoption of the technology is the healthcare sector. The people in need of healthcare services find it very expensive, this is particularly true in developing countries. With improvement in technology previously expensive hospital equipment have been redesigned using current technology. The developments have seen a trend known as remote healthcare or previously known as Telemedicine. As a result, this paper is an attempt to solve a healthcare problem facing the society. The main objective of the paper is to design a remote healthcare system. It is comprised of three main parts. The first part being detection of a fall, second being detection of electrocardiogram commonly referred to as ECG (heartbeat detection) and the last part is providing the detected data for remote viewing. Remote viewing of the data enables a doctor or health specialist to monitor a patient's health progress away from hospital premises.
\end{abstract}

Keywords: Remote health monitoring; fall detection; ECG; remote viewing

Article History: Received 20 February 2020; Accepted 18 April 2021; Available online: 20 Aoril 2021

DOI: $10.14710 /$ jbiomes2021.v1i1.32-38

\section{INTRODUCTION}

A remote health monitoring system is an extension of a hospital medical system where a patient's vital body state can be monitored remotely. Traditionally, the detection systems are only found in hospitals and are characterized by huge and complex circuitry which requires high power consumption. Continuous advances in the semiconductor technology industry have led to sensors and microcontrollers that are smaller in size, faster in operation, low in power consumption and affordable in cost[1].

In recent time, several systems have come up to address the issue of remote health monitoring. The systems have a wireless detection system that sends the sensor information wirelessly to a remote server [2-4]. Some have even adopted a service model that requires one to pay a subscription fee. In developing countries, this is a hindrance as some people cannot use them due to cost issue involved [5]. There is also the issue of internet connectivity where some systems to operate good quality internet for a real-time remote connection is required [6].

Many of the systems introduce work best in the developed countries where the infrastructure is working perfectly. In most cases the systems are adapted to work in developing countries. To reduce some of these problems, there is need to approach the remote detection from a ground up approach to suit the basic minimal conditions presently available in developing countries.

A simple patient monitoring system design can be approached by the number of parameters it can detect. In some instances, by detecting one parameter, several readings can be calculated. For simplicity considerations, parameter detections include single parameter and multi-parameter [7][8].

Remote health monitoring can provide useful physiological information in the home. This monitoring is useful for elderly or chronically ill patients who would like to avoid a long hospital stay [6] [9]. Wireless sensors are used to collect and transmit signals of interest and a processor is programmed to receive and automatically analyze the sensor signals [9], and even can be programmed for prescription [10].

In this paper, we are to choose appropriate sensors according to what we would like to detect and design algorithms to realize our detection. Examples are detection of a fall, monitoring cardiac signals, brain signal monitoring (EEG), and in-home ultrasound [11].

Using a single parameter monitoring system, an approach to a remote health monitoring system is designed that extends healthcare from the traditional clinic or hospital setting to the patient's home. The system is to collect a heartbeat detection system data and a fall detection system data. The data from the two single parameter monitoring systems is then availed for remote detection.

\section{Materials ANd Methods}

\subsection{Design of fall detection system}

The sensor chosen for fall detection is an accelerometer. Two common types of accelerometers available are the twoaxis and three-axis. The sensitivity of the accelerometer determines its cost with the most sensitive being costly. 


\subsubsection{Fall detection description}

In this paper, a simple tri-axis accelerometer is chosen. The accelerometer could detect three values along the $\mathrm{X}, \mathrm{Y}$ and $\mathrm{Z}$ axes. With the aid of a microcontroller and suitable algorithm, data from the accelerometer is used to detect a fall. This is then transferred wirelessly for data logging to be viewed remotely by a medical specialist or person interested in the data.

With the accelerometer axis data, a threshold value is set. Using the dot product or cross product of the axis data and comparing it with the threshold, a fall detection can be achieved [12]. The microcontroller then transmits the data wirelessly to a local database that can be accessed remotely.

A crucial factor to consider while using accelerometers for fall detection is that the readings achieved could give false fall detection [13]. To prevent this, placement of the fall sensor is very important. Using various sample test data achieved during the design and following up on past research on the subject study, optimal sensor placement is at a central part of the body. The waist section is found to be a considerable position for best detection [14].

It is important to note that a modern smartphone has an accelerometer within its circuit board. The accelerometer can be accessed through the library and an application made to detect and record a fall [15]. During the design consideration, a smartphone method is ruled out since the phone would end up being damaged during a fall. The method chosen is a low cost and noninvasive alternative to the user. Since the device is being used by a person prone to falls, the device is also expected to survive several falls and knocks.

\subsubsection{Implementation}

Development is done with an accelerometer(ADXL335), microcontroller(ATmega328), and wireless transceiver (HC11 $433 \mathrm{MHz}$ ) in transmission mode only.

To detect fall along an axis, the acceleration magnitude (AM) is considered. This is achieved by a magnitude vector. Consider:

$$
A M=\sqrt{ }\left(a_{x}^{2}+a_{y}^{2}+a_{z}^{2}\right)
$$

Where AM is acceleration magnitude.

With the accelerometer output data, the angle change can also be calculated using the dot product. To achieve this, the instantaneous vector and a reference vector are introduced. Instantaneous vector is given by

$$
\mathrm{a}=\left(\mathrm{a}_{\mathrm{x}}, \mathrm{a}_{\mathrm{y}}, \mathrm{a}_{\mathrm{z}}\right)
$$

Reference vector is generated when a user stands up. It is given by

$$
\mathrm{b}=\left(\mathrm{b}_{\mathrm{x}}, \mathrm{b}_{\mathrm{y}}, \mathrm{b}_{\mathrm{z}}\right)
$$

Using both the instantaneous vector and reference vector in the following formula

$$
\text { a. } b=|a||b| \cos \theta
$$

Making the angle as subject

$$
\theta=\cos -1(a \cdot b /|a||b|)
$$

The flowchart for fall detection algorithm shown in Fig.1 indicates the microcontroller steps as follows:

1. Set a threshold value.

2. Detect if an acceleration exceeds the threshold.

3. Waits for acceleration to subside and return to relatively normal acceleration.

4. Check user's orientation.

5. If user is parallel to the ground, a fall is detected.

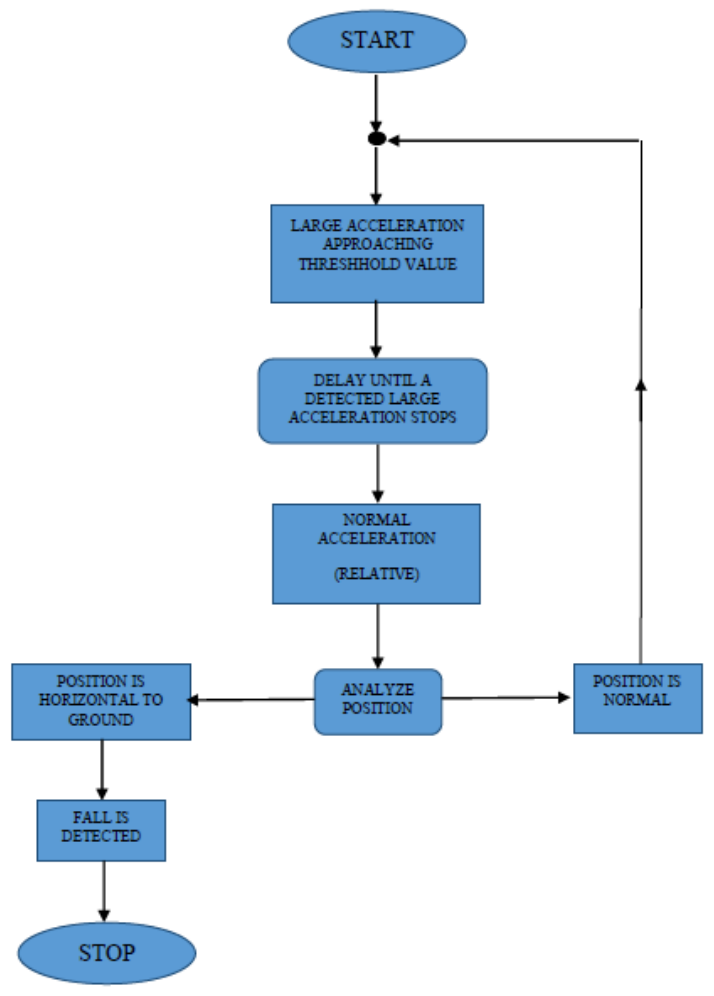

Fig.1 Flowchart for fall detection algorithm

Table $1 \mathrm{X}, \mathrm{Y}$, and $\mathrm{Z}$ axes calibration

\begin{tabular}{|c|c|c|}
\hline & $\mathbf{5}$ volt & 3.3 volt \\
\hline X axis & $a_{x}=\frac{\left(\frac{A D C_{x} \times 5}{1024}\right)-1.64}{0.5}$ & $a_{x}=\frac{\left(\frac{A D C_{x} x 3.3}{1024}\right)-1.64}{0.33}$ \\
\hline Y axis & $a_{y}=\frac{\left(\frac{A D C_{y} \times 5}{1024}\right)-1.63}{0.5}$ & $a_{y}=\frac{\left(\frac{A D C_{y} x 3.3}{1024}\right)-1.63}{0.33}$ \\
\hline Z axis & $a_{z}=\frac{\left(\frac{A D C_{z} \times 5}{1024}\right)-1.65}{0.5}$ & $a_{x}=\frac{\left(\frac{A D C_{z} x 3.3}{1024}\right)-1.65}{0.33}$ \\
& & \\
\hline
\end{tabular}


The accelerometer readings are converted to a digital value using an analog to digital conversion(ADC) in the microcontroller. The base voltage could either be 3.3 volts or 5 volts. If the system is to be designed with emphasis on energy saving, the 3.3 volts would fit best. Table 1 summarizes formula used for the $\mathrm{X}, \mathrm{Y}$ and $\mathrm{Z}$ axes calibration. Where ADCX, ADCy, and $\mathrm{ADCz}$ for $\mathrm{X}, \mathrm{Y}$ and $\mathrm{Z}$ axes respectively are digital values after analog signal from accelerometer has been passed into the ADC in the microcontroller. From Eq.1, AM value is then compared for fall detection using $\mathrm{AM}>1.8 \mathrm{~g}$.

\subsubsection{Microcontroller(ATmega328)}

The ATmega328 is a very popular board among hobbyists and is the microcontroller board of choice when building small model projects. Because of this, there are extensive tutorials and open source examples available to facilitate learning and familiarizing oneself with the board. In addition to this, we choose this board because of the following characteristics:

1. Operating voltage - The operating voltage of $5 \mathrm{~V}$ with a $3.3 \mathrm{~V}$ option is appropriate because both our sensor boards and Bluetooth module operate under 5 or $3.3 \mathrm{~V}$ power and output readings in the range of $0-5 \mathrm{~V}$.

2. Input voltage - The board has a built-in voltage regulator that allows an input voltage range of $7-12 \mathrm{~V}$, which is suitable because we plan to power the board with a $9 \mathrm{~V}$ battery.

3. Memory - The flash memory $(32 \mathrm{~KB})$ is appropriate because our algorithm programs can be fairly long and require a decent amount of memory on the microcontroller to store them. The Static Random Access Memory(SRAM) (2KB) is a little on the low side, but the algorithms can work around this by not storing too many variables, so as to not exhaust the SRAM capacity.

4. Specialty pins - The Arduino Uno comes with RX/TX pins, which will be used for serial communication with our Bluetooth module. The board also comes with I2C compatible pins, which will be crucial to interface with our digital accelerometer.

\subsubsection{Sensor}

For appropriate fall detection, we choose an accelerometer. The model selected is the ADXL345 triple axis digital accelerometer. It has a wide G-range (up to $\pm 16 \mathrm{~g}$ ). The range is very wide considering some severe falls are rated at $8 \mathrm{~g}$ 's. Since it is a digital sensor, the resolution can be adjusted and there is less voltage noise, and less calibration. The ADXL345 gives tri-axial data and requires a minimum of $3.3 \mathrm{~V}$ power, is $\mathrm{I} 2 \mathrm{C}$ compatible and thus our microcontroller board can interface with it correctly.

For wireless communication, the wireless transceiver model HC11 (433 MHz) is chosen. Its specifications include transmission of data up to 1 Kilometer, supports RX/TX serial communication from $9600 \mathrm{bps}-115200 \mathrm{bps}$ (bits per second, baud rate), which makes it fully compatible with our AtMega328 microcontroller. For remote viewing purposes, data obtained in the fall detection is referred as DATA1.

\subsection{Design of cardiac detection system}

The detector is based on a method that is non-invasive to the user. As a result, a method involving use of infrared light is devised. It is based on the principle of photoplethysmography(PPG). The blood volume variation occurs in body tissues as the blood is pumped by the heart. The variation is detected by a light source and a detector and can be used to calculate the heartbeat. There are two methods the PPG can be employed. They are:

1. Transmittance method - the infrared light is transmitted through a body tissue into an infrared receiver on the opposite side. The resultant light is then used in heartbeat detection. There is limited penetration depth of the light through the organ tissue, as a result the transmittance PPG is applicable to a restricted body part, such as the finger or the ear lobe.

2. Reflectance method depends on reflected light into a receiver. This is the method chosen in the paper.

\subsubsection{Cardiac signal detection using reflectance method}

The light is emitted into the finger tissue and the reflected light is measured by the detector. The light does not have to penetrate the body, the reflectance PPG can be applied to any parts of human body. Tissue blood volume is responsible for fluctuation of light absorbed.

The detected PPG signal has both AC and DC components. The pulsating changes in arterial blood volume cause the AC component. This is the component that is synchronous with the heartbeat. It is therefore the source of signal of interest. The DC component of the detected PPG signal is as a result of the tissues and the average blood volume. The $\mathrm{AC}$ component is superimposed onto a large DC component. AC component must be removed from the $\mathrm{DC}$ component to acquire an $\mathrm{AC}$ waveform with a high signal-to-noise ratio. AC amplification is thus done to acquire necessary signal of interest with the heartbeat information.

\subsubsection{Implementation using reflectance method}

To acquire the heartbeat signal of interest, the output from the infrared detector is fed through a comparator. Output from detector is first filtered using a two stage High PassLow Pass circuit. The signal is then digitized using an analog to digital converter. The digitization is done using a microcontroller. Using an algorithm, a digital value of the heartbeat can be displayed on an liquid-crystal display(LCD) as shown in Fig.2.

The comparator used is OPAMP(LM324). The detector output is compared to a threshold voltage. For the first stage, inverting terminals of the OPAMP is connected to voltage divider which is set at threshold voltage.

The non-inverting terminal is connected to the detector through 1-microfarad capacitor. When the body tissue is illuminated, the intensity of light reduces. As detected light intensity reduces, the resistance increases causing an increase in the voltage drop. 


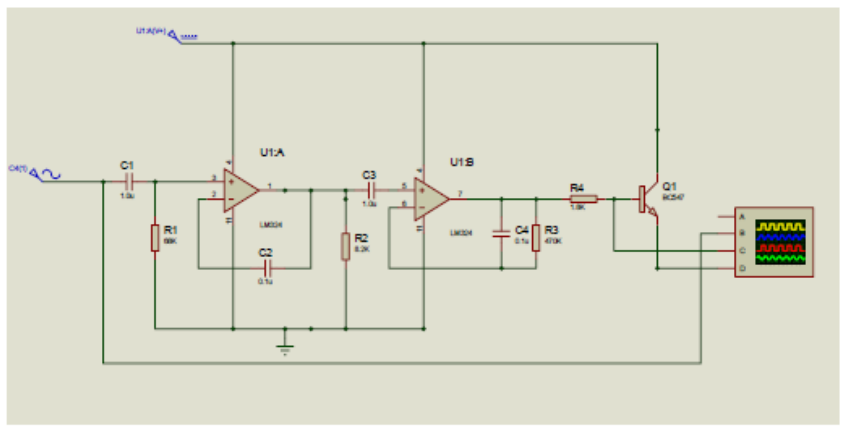

Fig.2 Circuit schematic for heartbeat detection

The following two scenarios arise from Fig.2:

a. When high, a voltage drop across the detector that is input into the non-inverting input exceeds that of inverting input. A logic high is developed at comparator output. This is useful for detecting the high peak in the heart beat ( $\mathrm{R}$ in Fig.3).

b. Voltage drop across detector is less than that of inverting input. Output is a series of pulses that can be input into microcontroller. This assists in detecting any small peak between the major peak in a heartbeat (P,T,U in Fig.3).

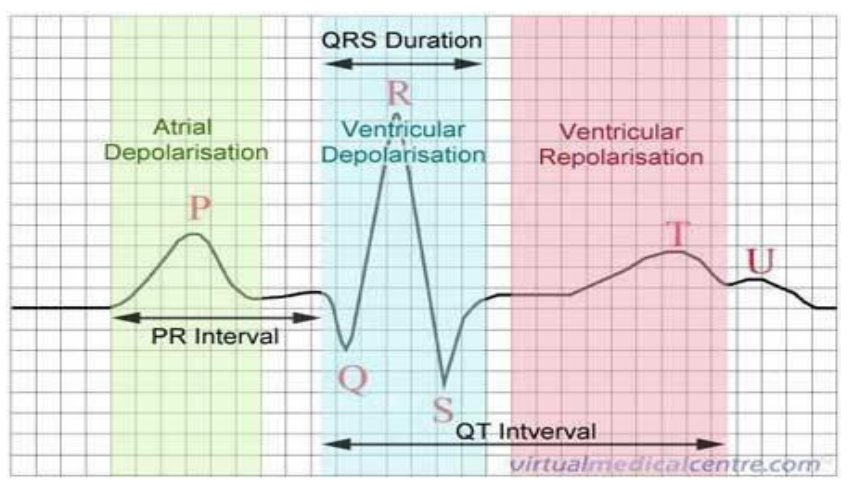

Fig.3 Representation of a heartbeat

In Fig.2, detector passes more current when it receives more light which in turn causes a voltage drop to enter amplifier circuit. Two consecutive operational amplifier stages to filter out noise and emphasize the peaks. The OPAMPS are contained in the same IC and operates at a single power supply of 5 volts DC. The filtering is necessary to block higher frequency noises present in the signal.

A 1-uF capacitor at the input of each stage is required to block the DC component in the signal. The two stage amplifier/filter provides sufficient gain to boost the weak signal from the photo sensor unit and convert it into a pulse.

The frequencies of interest using Beats Per Minute(BPM) (f = BPM/60) notation are defined as:

i) Normal heart rhythm(Normal sinus rhythm) which is between 60 BPM to 100 BPM.

ii) Fast heart rhythm(BPM $>100 \mathrm{BPM})$. If the BPM is in this region, it could indicate a heart condition known as Tachycardia.

iii) Slow heart rhythm(less than $60 \mathrm{BPM})$. If the BPM is in this region, it could indicate a heart condition known as Bradycardia.

\subsection{Design of the remote detection system}

Data from the fall detector (DATA1) and heartbeat detection system (DATA2) is transferred for remote viewing. DATA1 is transferred through a wireless transceiver from Atmega328 and received by another Atmega328. Both DATA1 and DATA2 are transferred serially to the Raspberry Pi as shown in Fig.4.

Raspberry Pi has a Broadcom chip. It has a scaled down version of Linux OS ( Raspbian Jessie) running on it. This provides an environment for access of the General Purpose Input Output pins (GPIO) for external circuit to be connected to it. For remote viewing of the fall detection data (DATA1) and heartbeat detection data (DATA2), the Raspberry Pi acts as a server. With the Raspberry Pi, the main objective of the our research "remote health detection system" is achieved.

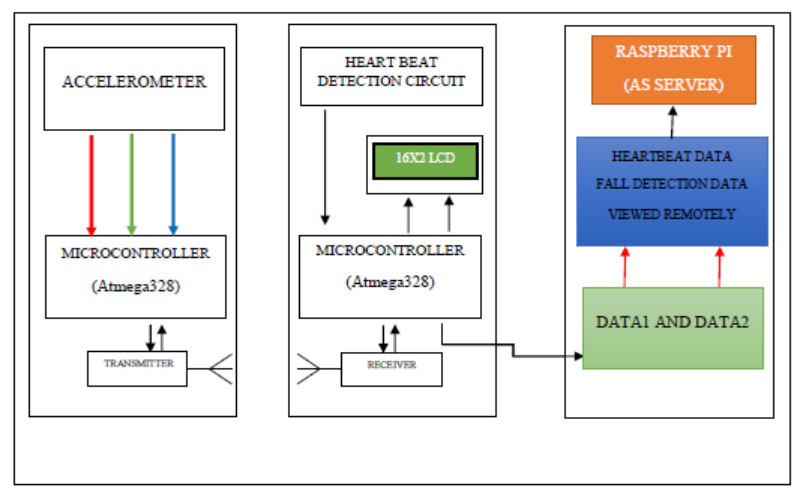

Fig..4 System block representation

\section{RESUlts AND DiscuSSION}

\subsection{Fall detection results}

The result of fall detection mechanism for different test conditions is shown in Table 1-6. Table 1 shows the results when accelerometer at rest on table $(X=0, Y=0, Z=90)$. Table 2 shows the results when accelerometer at upside down on table axis tilt $(\mathrm{X}=0, \mathrm{Y}=180, \mathrm{Z}=180)$. Table 3 shows the results when accelerometer at axis tilt sensor facing user $(\mathrm{X}=0, \mathrm{Y}=+90, \mathrm{Z}=+90$ (or 180)). Table 4 shows the results when accelerometer at axis tilt sensor facing comp $(\mathrm{X}=0, \mathrm{Y}=$ $-90, Z=-90($ or 0$)$ ). Table 5 shows the results when accelerometer at axis tilt sensor to the left sideways $(X=+90$, $\mathrm{Y}=0, \mathrm{Z}=-90$ (or 180)). Table 6 shows the results when accelerometer at axis tilt sensor to the right-sideways $(X=$ 90, $\mathrm{Y}=0, \mathrm{Z}=90$ (or 0$)$ ).

Table 1 Accelerometer resting face up $(X=0, Y=0, Z=90)$

\begin{tabular}{|l|l|l|}
\hline $\mathrm{X}=331$ & $\mathrm{Y}=335$ & $\mathrm{Z}=406$ \\
\hline $\mathrm{X}=335$ & $\mathrm{Y}=339$ & $\mathrm{Z}=409$ \\
\hline $\mathrm{X}=331$ & $\mathrm{Y}=335$ & $\mathrm{Z}=406$ \\
\hline $\mathrm{X}=335$ & $\mathrm{Y}=339$ & $\mathrm{Z}=410$ \\
\hline $\mathrm{X}=331$ & $\mathrm{Y}=335$ & $\mathrm{Z}=406$ \\
\hline $\mathrm{X}=332$ & $\mathrm{Y}=336$ & $\mathrm{Z}=406$ \\
\hline $\mathrm{X}=332$ & $\mathrm{Y}=335$ & $\mathrm{Z}=406$ \\
\hline $\mathrm{X}=332$ & $\mathrm{Y}=336$ & $\mathrm{Z}=406$ \\
\hline $\mathrm{X}=331$ & $\mathrm{Y}=335$ & $\mathrm{Z}=406$ \\
\hline $\mathrm{X}=331$ & $\mathrm{Y}=336$ & $\mathrm{Z}=408$ \\
\hline $\mathrm{X}=335$ & $\mathrm{Y}=339$ & \\
\hline
\end{tabular}


Table 2 Accelerometer upside down on table axis tilt $(\mathrm{X}=0$, $\mathrm{Y}=180, \mathrm{Z}=180$ )

\begin{tabular}{|l|l|l|}
\hline $\mathrm{X}=329$ & $\mathrm{Y}=327$ & $\mathrm{Z}=271$ \\
\hline $\mathrm{X}=330$ & $\mathrm{Y}=327$ & $\mathrm{Z}=271$ \\
\hline $\mathrm{X}=329$ & $\mathrm{Y}=327$ & $\mathrm{Z}=271$ \\
\hline $\mathrm{X}=330$ & $\mathrm{Y}=326$ & $\mathrm{Z}=271$ \\
\hline $\mathrm{X}=329$ & $\mathrm{Y}=326$ & $\mathrm{Z}=271$ \\
\hline $\mathrm{X}=329$ & $\mathrm{Y}=326$ & $\mathrm{Z}=271$ \\
\hline $\mathrm{X}=329$ & $\mathrm{Y}=326$ & $\mathrm{Z}=271$ \\
\hline $\mathrm{X}=329$ & $\mathrm{Y}=326$ & $\mathrm{Z}=271$ \\
\hline $\mathrm{X}=330$ & $\mathrm{Y}=326$ & $\mathrm{Z}=271$ \\
\hline $\mathrm{X}=329$ & $\mathrm{Y}=326$ & $\mathrm{Z}=271$ \\
\hline
\end{tabular}

Table 3 Accelerometer facing user $(X=0, Y=+90, Z=+90$ (or 180))

\begin{tabular}{|l|l|l|}
\hline $\mathrm{X}=263$ & $\mathrm{Y}=335$ & $\mathrm{Z}=338$ \\
\hline $\mathrm{X}=263$ & $\mathrm{Y}=335$ & $\mathrm{Z}=337$ \\
\hline $\mathrm{X}=264$ & $\mathrm{Y}=333$ & $\mathrm{Z}=336$ \\
\hline $\mathrm{X}=263$ & $\mathrm{Y}=333$ & $\mathrm{Z}=336$ \\
\hline $\mathrm{X}=263$ & $\mathrm{Y}=333$ & $\mathrm{Z}=335$ \\
\hline $\mathrm{X}=264$ & $\mathrm{Y}=333$ & $\mathrm{Z}=337$ \\
\hline $\mathrm{X}=263$ & $\mathrm{Y}=333$ & $\mathrm{Z}=337$ \\
\hline $\mathrm{X}=264$ & $\mathrm{Y}=333$ & $\mathrm{Z}=337$ \\
\hline $\mathrm{X}=264$ & $\mathrm{Y}=333$ & $\mathrm{Z}=338$ \\
\hline $\mathrm{X}=263$ & $\mathrm{Y}=333$ & $\mathrm{Z}=339$ \\
\hline $\mathrm{X}=264$ & $\mathrm{Y}=333$ & $\mathrm{Z}=337$ \\
\hline
\end{tabular}

Table 4 Accelerometer top facing away from user $(\mathrm{X}=0, \mathrm{Y}=$ $-90, Z=-90($ or 0$))$.

\begin{tabular}{|l|l|l|}
\hline $\mathrm{X}=266$ & $\mathrm{Y}=329$ & $\mathrm{Z}=341$ \\
\hline $\mathrm{X}=264$ & $\mathrm{Y}=328$ & $\mathrm{Z}=341$ \\
\hline $\mathrm{X}=264$ & $\mathrm{Y}=328$ & $\mathrm{Z}=342$ \\
\hline $\mathrm{X}=264$ & $\mathrm{Y}=329$ & $\mathrm{Z}=342$ \\
\hline $\mathrm{X}=264$ & $\mathrm{Y}=328$ & $\mathrm{Z}=341$ \\
\hline $\mathrm{X}=264$ & $\mathrm{Y}=334$ & $\mathrm{Z}=346$ \\
\hline $\mathrm{X}=264$ & $\mathrm{Y}=331$ & $\mathrm{Z}=342$ \\
\hline $\mathrm{X}=264$ & $\mathrm{Y}=332$ & $\mathrm{Z}=341$ \\
\hline $\mathrm{X}=264$ & $\mathrm{Y}=332$ & $\mathrm{Z}=341$ \\
\hline $\mathrm{X}=264$ & $\mathrm{Y}=332$ & $\mathrm{Z}=342$ \\
\hline $\mathrm{X}=264$ & $\mathrm{Y}=332$ & $\mathrm{Z}=341$ \\
\hline $\mathrm{X}=263$ & $\mathrm{Y}=331$ & $\mathrm{Z}=340$ \\
\hline
\end{tabular}

Table 5 Accelerometer left tilt detection $(X=+90, Y=0, Z=$ $-90($ or 180$)$ ).

\begin{tabular}{|l|l|l|}
\hline $\mathrm{X}=398$ & $\mathrm{Y}=328$ & $\mathrm{Z}=339$ \\
\hline $\mathrm{X}=400$ & $\mathrm{Y}=329$ & $\mathrm{Z}=340$ \\
\hline $\mathrm{X}=398$ & $\mathrm{Y}=328$ & $\mathrm{Z}=340$ \\
\hline $\mathrm{X}=399$ & $\mathrm{Y}=328$ & $\mathrm{Z}=340$ \\
\hline $\mathrm{X}=399$ & $\mathrm{Y}=328$ & $\mathrm{Z}=339$ \\
\hline $\mathrm{X}=399$ & $\mathrm{Y}=329$ & $\mathrm{Z}=340$ \\
\hline $\mathrm{X}=398$ & $\mathrm{Y}=328$ & $\mathrm{Z}=340$ \\
\hline $\mathrm{X}=399$ & $\mathrm{Y}=328$ & $\mathrm{Z}=341$ \\
\hline $\mathrm{X}=399$ & $\mathrm{Y}=329$ & $\mathrm{Z}=341$ \\
\hline $\mathrm{X}=399$ & $\mathrm{Y}=328$ & $\mathrm{Z}=341$ \\
\hline $\mathrm{X}=400$ & $\mathrm{Y}=329$ & $\mathrm{Z}=341$ \\
\hline $\mathrm{X}=399$ & $\mathrm{Y}=329$ & \\
\hline
\end{tabular}

Table 6 Accelerometer right tilt detection $(X=-90, Y=0$, $\mathrm{Z}=90$ (or 0$)$ ).

\begin{tabular}{|l|l|l|}
\hline $\mathrm{X}=333$ & $\mathrm{Y}=337$ & $\mathrm{Z}=410$ \\
\hline $\mathrm{X}=264$ & $\mathrm{Y}=336$ & $\mathrm{Z}=358$ \\
\hline $\mathrm{X}=266$ & $\mathrm{Y}=339$ & $\mathrm{Z}=336$ \\
\hline $\mathrm{X}=266$ & $\mathrm{Y}=336$ & $\mathrm{Z}=338$ \\
\hline $\mathrm{X}=264$ & $\mathrm{Y}=335$ & $\mathrm{Z}=335$ \\
\hline $\mathrm{X}=264$ & $\mathrm{Y}=334$ & $\mathrm{Z}=334$ \\
\hline $\mathrm{X}=265$ & $\mathrm{Y}=334$ & $\mathrm{Z}=334$ \\
\hline $\mathrm{X}=265$ & $\mathrm{Y}=333$ & $\mathrm{Z}=338$ \\
\hline $\mathrm{X}=266$ & $\mathrm{Y}=335$ & $\mathrm{Z}=335$ \\
\hline $\mathrm{X}=265$ & $\mathrm{Y}=334$ & $\mathrm{Z}=334$ \\
\hline $\mathrm{X}=265$ & $\mathrm{Y}=334$ & $\mathrm{Z}=334$ \\
\hline $\mathrm{X}=265$ & $\mathrm{Y}=333$ & \\
\hline
\end{tabular}

Test result as shown in Tables 1-6 indicate that the accelerometer is able to respond to the different position by sending different signal value from sensor. The values indicated here is its ADC value. On average, the corresponding $\mathrm{X}, \mathrm{Y}$ and $\mathrm{Z}$ values are with small fluctuation, thus it can be concluded that the fall system can respond correctly for different position the patient.

\subsection{Cardiac signal results}

The system for cardiac signal has been tested. Fig. 5 shows the result of first stage of OPAMP output, while Fig.6 shows the result of second stage of OPAMP output. Fig.7 shows the result of second stage of OPAMP output with infrared sensor input.

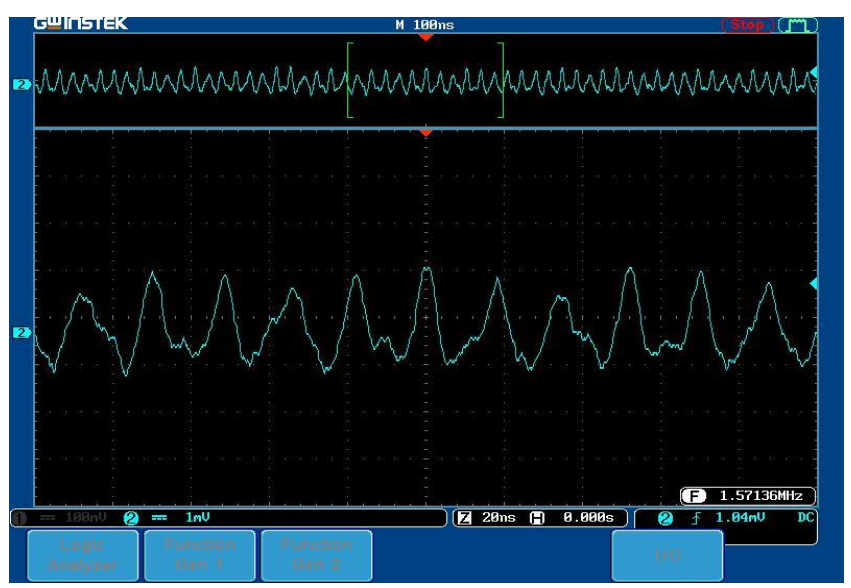

Fig.5 First stage of OPAMP output

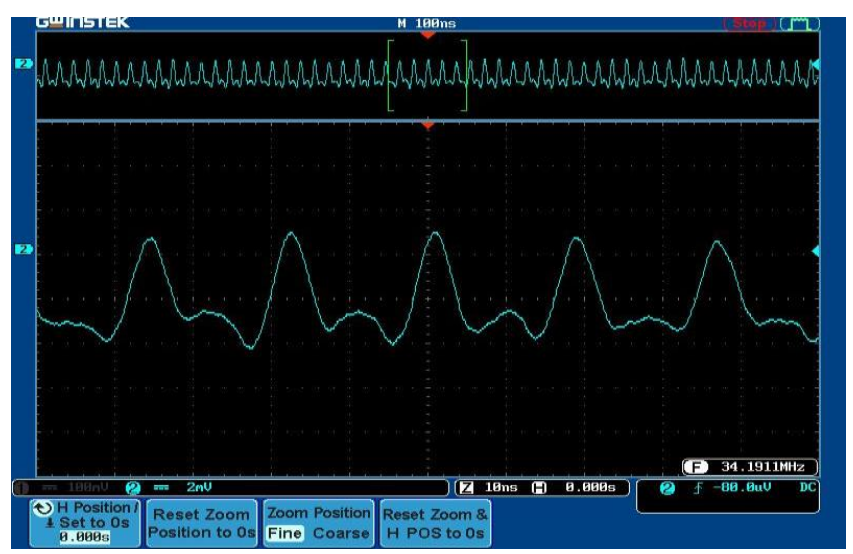

Fig.6 Second stage of OPAMP output 


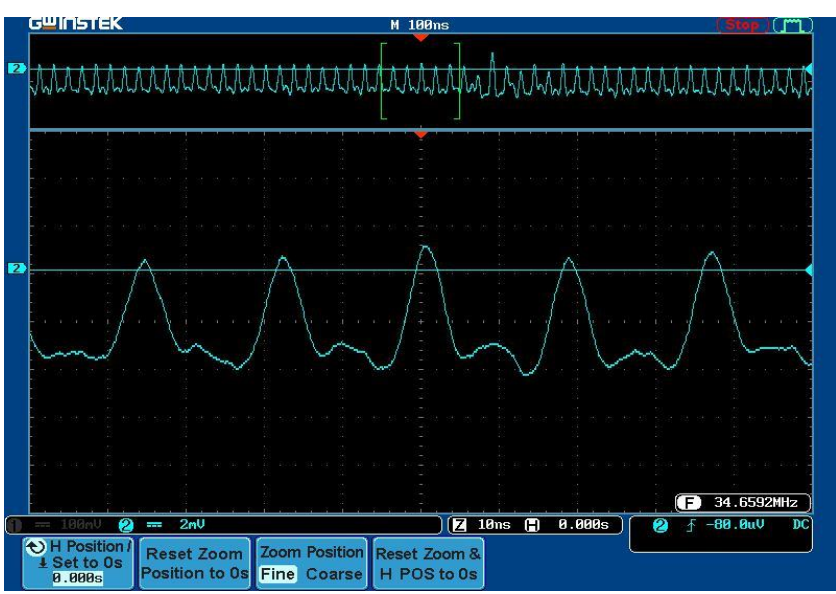

Fig.7 Second stage of OPAMP output with infrared sensor input

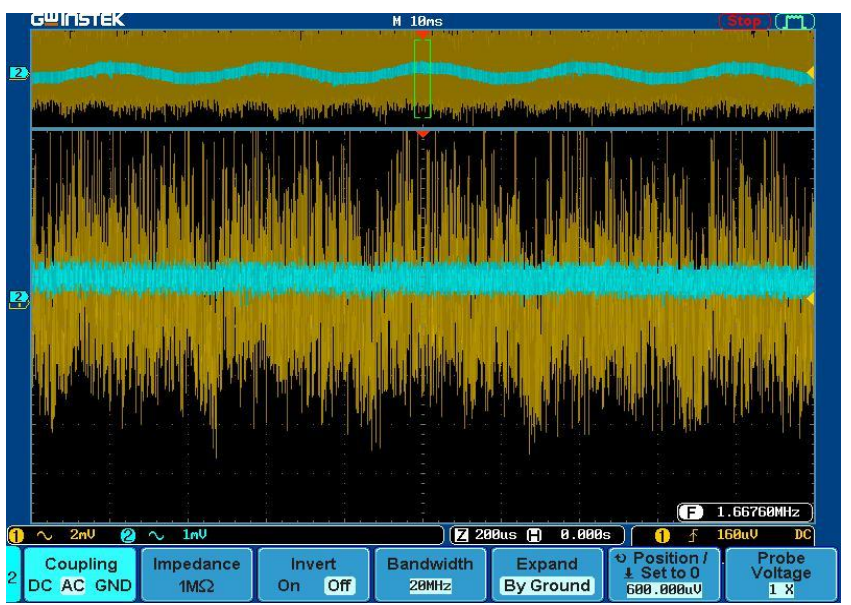

Fig.8 Comparison of input and output signal seen as a stream

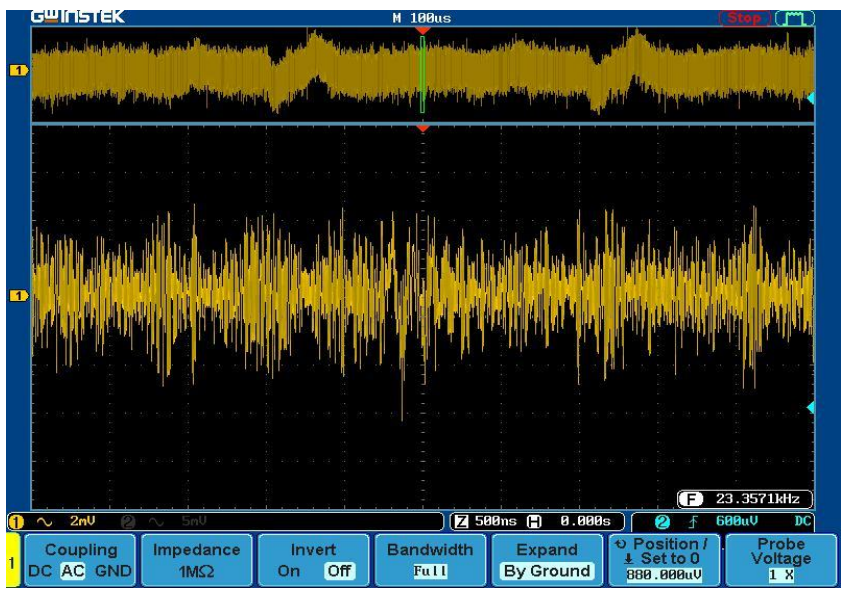

Fig.9 output signal seen as a stream on an oscilloscope

Fig. 8 shows the result of comparison of input and output signals seen as a stream. Moreover, Fig.9 shows output signal seen as a stream on an oscilloscope. Form this result, the heart beat can be detected.

\subsection{Raspberry Pi results}

The process in Raspberry $\mathrm{Pi}$ sends processed signal to be displayed. Fig.10 shows Linux terminal GPIO access screenshot, representing the signals in each I/O port. Fig.11 shows remote access Local Area Network (LAN) addressing. Both figures indicate the proof of concept for the remote health monitoring system.

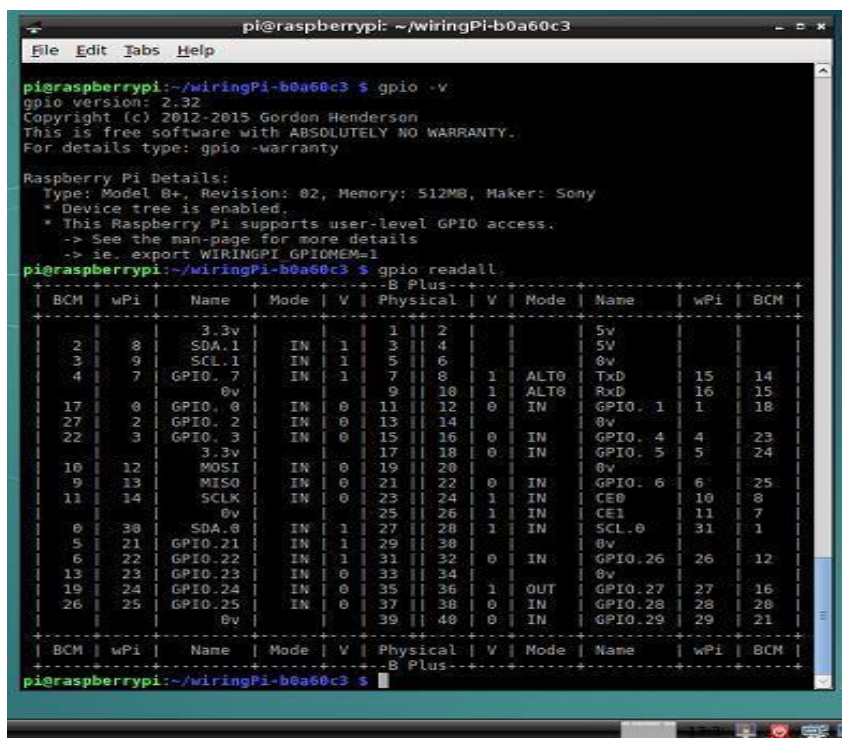

Fig.10 Linux terminal GPIO access screenshot

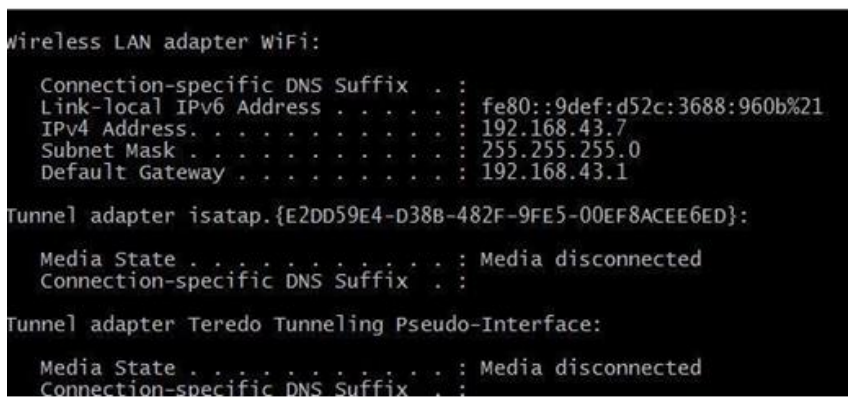

Fig.11 Remote access LAN Addressing

\section{Conclusion}

The main objective of the experiment was successfully achieved. All the three individual modules namely heart beat detection module, fall detection module and remote viewing module gave out the intended results. The designed system modules can further be optimized and produced to a final single circuit. More important fact that came up during the design is that all the circuit components used in the remote health detection system are available locally. With development in the integrated circuit industry, Micro Electro Mechanical Systems (MEMs) and microcontrollers have become affordable, have increased processing speeds, miniaturized and power efficient. This has led to increased development of embedded systems that the healthcare specialists are adopting. These embedded systems have also 
been adopted in the smartphone technology. With increased internet penetration in most developing countries through mobile phones, its uses such as Internet of things (IoT) will become adopted at a faster rate. The remote healthcare system utilizes these concepts to come up with a system for better quality of life for people in society.

\section{REFERENCES}

[1] Y. Huang, and K. Newman, "Improve quality of care with remote activity and fall detection using ultrasonic sensors, " Annual International Conference of the IEEE Engineering in Medicine and Biology Society, USA, 2012.

[2] Chung, Wan-Young, Chiew-Lian Yau, Kwang-Sig Shin, and Risto Myllyla. "A cell phone based health monitoring system with self analysis processor using wireless sensor network technology." In 2007 29th Annual International Conference of the IEEE Engineering in Medicine and Biology Society, pp. 3705-3708. 2007.

[3] Sathya, Duraisamy, and Pugalendhi Ganesh Kumar. "Secured remote health monitoring system." Healthcare technology letters 4, no. 6 (2017) $228-232$.

[4] Mahmud, Md Shaad, Honggang Wang, A. M. Esfar-E-Alam, and Hua Fang. "A wireless health monitoring system using mobile phone accessories." IEEE Internet of Things Journal 4, no. 6 (2017): 2009-2018.

[5] Ohta, Shigeru, Hiroshi Nakamoto, Yoshimitsu Shinagawa, and Tomohiro Tanikawa. "A health monitoring system for elderly people living alone." Journal of telemedicine and telecare 8, no. 3 (2002): 151-156.

[6] S. Gong, Y. Wang, M. Zhang, and C. Wang, "Design of remote elderly health monitoring system based on MEMS sensors, " IEEE International Conference on Information and Automation, China, 2017.

[7] M. Saranya, R. Preethi, M. Rupasri, and S. Veena, "A survey on health monitoring system by using IOT, "International Journal for Research in
Applied Science \& Engineering Technology, Vol.6, Issue III, PP.778-782, 2018.

[8] Mansor, Hasmah, MHA Shukor, SS Meskam, NQAM Rusli, and NS Zamery. "Body temperature measurement for remote health monitoring system." In 2013 IEEE International conference on smart instrumentation, measurement and applications (ICSIMA), pp. 1-5. IEEE, 2013.

[9] Korhonen, Ilkka, Juha Parkka, and Mark Van Gils. "Health monitoring in the home of the future." IEEE Engineering in medicine and biology magazine 22, no. 3 (2003): 66-73.

[10] Majzoob K. Omer, Osama E. Sheta, Mohamed S. Adrees, Deris Stiawan, Munawar A Riyadi, Rahmat Budiarto , Deep Neural Network for Heart Disease Medical Prescription Expert System, Indonesian Journal of Electrical Engineering and Informatics (IJEEI), vol. 6 no 2 (2018), 217-224. [11] L. Malasinghe, N. Ramzan, and K. Dahal, " Remote patient monitoring: a comprehensive study, " Journal of Ambient Intelligence and Humanized Computing, Vol.10, Issue 1, PP.57-76, 2019.

[12] Bagala, Fabio, Clemens Becker, Angelo Cappello, Lorenzo Chiari, Kamiar Aminian, Jeffrey M. Hausdorff, Wiebren Zijlstra, and Jochen Klenk. "Evaluation of accelerometer-based fall detection algorithms on real-world falls." PloS one 7, no. 5 (2012): e37062.

[13] Abbate, Stefano, Marco Avvenuti, Guglielmo Cola, Paolo Corsini, Janet Light, and Alessio Vecchio. "Recognition of false alarms in fall detection systems." In 2011 IEEE Consumer Communications and Networking Conference (CCNC), pp. 23-28. IEEE, 2011.

[14] Bourke, A. K., P. Van de Ven, M. Gamble, R. O'Connor, K. Murphy, E. Bogan, E. McQuade, P. Finucane, G. Olaighin, and J. Nelson. "Evaluation of waist-mounted tri-axial accelerometer based fall-detection algorithms during scripted and continuous unscripted activities." Journal of biomechanics 43, no. 15 (2010): 3051-3057.

[15] $\mathrm{He}, \mathrm{Yi}, \mathrm{Ye} \mathrm{Li}$, and Shu-Di Bao. "Fall detection by built-in triaccelerometer of smartphone." In Proceedings of 2012 IEEE-EMBS International Conference on Biomedical and Health Informatics, pp. 184187. IEEE, 2012. 